\title{
Literature Review on China's Medical Service Supply System Reform
}

\author{
JIANG Xue \\ North China Electric Power University, Human and Social Science School, China, 102206 \\ 596566037@qq.com
}

\begin{abstract}
Key words: medical reform, government dominance, marketization, government provision, public service.

Abstract: The marketization orientation of medical system reform of China is one of the hotspots for governmental decision-making departments and the theoretical circle. And the medical service supply system has been debated for years in academia. Scholars have made in-depth researches and discussions on a series of issues such as the orientation of the government's responsibility in medical system reform and the medical reform path for public hospitals, which are worthy of being further considered.
\end{abstract}

\section{Research on Medical Service Market}

Arrow (1963) pointed out in his researches on medical service market that patients are in a disadvantageous information position in medical market, which has increased risks and uncertainties when they are consuming medical services. A false judgment is likely to result in a wrong selection, which in return will generate a rather higher cost. Compared with other goods, medical services are featured by unchangeability, unrepeatability and irreversibility in many cases.

By comparing medical market with markets of common goods, economist Stiglitz (1988) found that the former has strong particularities, like its highly asymmetrical information.

Wang Yong et al. (2005) analyzed the differences between markets of common goods and medical service market, and discovered that the increase of supply tend to result in the price fall in the markets of common goods; the contrary is the case in medical market. To be specific, in case of an increase in supply, hospitals will use the highly asymmetrical information hospital-patient to produce induced demands.

\section{Medical System Defects of China}

Based on the current situation of reform, Zhu Hengpeng (2008) stated that there are fundamental defects in China's medical system: high barriers to entry and insufficient supply of medical services caused by excessive regulations; inappropriate price regulation, incentive mechanism and allocation of medical resources; public spending on health obviously focusing on large cities and the rich; and unbalanced allocation of medical resources.

After reviewing the documents related to medical systems issued by the Party Central Committee since the founding, Gao Chunliang, Mao Fengfu and Yu Hui (2009) held that financial constraint, path dependence and interest group are the main three factors limiting the deepening of medical system reform. Therefore, they proposed to decrease cost by introducing competition, boost medical system reform by improving social medical insurances, eliminate impacts of vested interest groups, and get rid of the administrative monopoly.

By concluding achievements and problems of medical and health care system, Feng Jin and $\mathrm{Yu}$ Yangyang (2008) argued that heavy medical burden, limited effect of medical insurances and 
insufficient equity are closely related to the market distortion. The key of medical reform is to establish a suitable incentive mechanism to control medical fees and guarantee the quality of medical services. In the aspect of medical services provision, establishing a competitive medical service market can facilitate form an equal doctor-patient relationship, reduce medical costs and improve work efficiency.

\section{Government’s Responsibility Orientation in Supply of Medical Health}

Argument on government dominance and market dominance. The argument on "government dominance" and "market dominance" has been a long-standing issue in China's medical and health care system reform. The source of soaring medical expenses and difficulty of getting medical service is boiled down to marketization or excessive government interventions by some people. In terms of medical services supply and basic drugs supply, what should the government do, to positively intervene or to let the market dominate the allocation of resources? The government's responsibility boundary in the supply of medical and health care services is the first thing must be made clear.

Government Dominance. Based on the theory of public service supply, self-interest behaviors have impeded the efficient voluntary payments to public goods, so public services cannot be effectively supplied via the market. Besides, goods with externalities (including personal goods) also can lead to inefficient output and thus require the provision of government. Apart from the fields of public goods and externality, information incompleteness, natural monopoly industries and help-the-poor programs for fairness, efficient supply can't be realized through market, and thus should be incorporate into the general responsibilities of the government's supply public service.

Many scholars are in favor of the view that medical and health care services shall be mainly supplied by the government, who should increase input in public hospitals, and governmental hospitals and social non-profit hospitals should become the main body in health services system so as to embody social public welfare nature of health care causes.

For instance, Li Ling (2008a) thought that the direction of medical system reform should become the supplementary of market dominated by the government. In addition, she also indicated that at present, China's medical system is faced with the problems of government incompetence and market failure which are caused by malpositioning transformation of government functions.

$\mathrm{Yu}$ Baorong (2008) showed the necessity to strengthen the government's responsibilities from the perspective of fairness, who held that our national basic health care system must embody the principle of "equality in priority, and giving consideration to efficiency". The biggest drawback to China's health care system lies in the government's failure to bear its responsibilities (such as protecting customers and social vulnerable groups) and excessive regulations (such as devoting too many efforts to establishing institutions). In short, roles of the government and market are not well dealt with.

Strengthening Marketization Orientation. Some scholars concluded that the problems in the existing medical system are caused by the government's excessive regulations rather than insufficient regulations, which has caused the failure of complete market mechanism operation. For example, Feng Zhanchun and Zhong Yanjun (2008) proposed that establishing medical security system requires medical service suppliers to establish the operation mechanism dominated by the market.

Some scholars microscopically pointed out the causes of problems such as high medical price, low input efficiency, and argued that the solution of them lies in the government's further deregulation. By analyzing China’s medical system and price regulation mode, Zhu Hengpeng 
(2007) found that the basic cause of high medical price is the two-directional monopoly of public medical institutions in pharmaceutical retailing. Besides, the underestimated medical services price, “compensation system for medical cost through drug-selling profits”, and rate-of-return regulation policy all induce hospitals to purchase and sell high-priced drugs. These problems are rooted from the government's regulation mispractices. Thus, weakening government regulations and breaking the monopoly of public hospitals are necessary.

Gu Xin (2005) pointed out that China's medical system reveals two abnormalities--extraordinarily rapid growth in medical expenses and decreased medical accessibility for low-income groups, reflecting serious problems in efficiency and equity of the whole medical system. The strategic selection of China's further medical system reform is not to abandon the marketization, but instead to choose the managed marketization.

Mr. Zhao Jie also expressed that hospitals should be competitive and layered; public hospitals are not the resistance of reform; and establishing medical services competitive system is of great importance.

Ding Kuili and Liu Jianping suggested that China should continue to promote the marketization of medical system reform and spend great efforts in introducing private hospitals to provide medical services. Most public hospitals provide basic medical services, while few public hospitals provide services of and scientific researches on difficult miscellaneous diseases. The positioning of private hospitals will be determined based on market demands by investors, thus helping the government avoid the previous input plight of casting a wide net and concentrate its financial resources on providing basic medical services.

\section{Government Responsibility in Medical Supply: Purchaser or Suppler?}

Direct Supply by Government. Arrow held that compared with those common goods, medical services have special properties. For example, there exists severe information asymmetry in the medical market, making medical consumption have the nature of "inductive consumption" to some extent, while patients often have no ability to examine the quality of medical services.

Furthermore, public medical services have properties of public goods or quasi-public goods. If all public medical services are put into the competitive market, some consumers would be ruled out the market, which may cause the unfairness of medical services.

Taking these into consideration, most countries choose their governments to directly supply medical services.

Purchase of Services by Government. The US adopts the mode of government's direct supply (public hospitals) and purchase of services (private hospitals), wherein the former lays emphasis on poverty people.

\section{Analysis on Supply of Medical Services}

Li Tianpin thought that controlled by the planned economy, hospitals have no autonomy in management, and remunerations of medical staffs have nothing to do with their services amount before the reform, so hospitals do not add treatment programs and quantity of drugs to increase cost incentive, and the average cost curve of medical services is at a real level. However, the orientation of marketization reform and decreased input in public hospitals year by year after the reform enable health authorities to delegate powers to public hospitals.

From the perspective of property right and operating mode, medical services suppliers can be divided into public hospitals, private non-profitable hospitals and private profitable hospitals.

Prevalence of Non-profitable Hospitals. 
Low Contract Cost of Ownership Form. As to the reasons why non-profitable hospitals are prevalent, most researches hold that non-profitable organizational form cannot get a minimized transaction cost under information asymmetry and third party payment. (Sloan, 2000)

From the analysis of Arrow (1963), uncertainty of therapeutic effects exists in the medical market, and treatment risks caused by such uncertainty have no corresponding insurance market, so customers can purchase insurances to eliminate such uncertainty. However, non-profitable hospitals are not pure pursuers of profit, who thus will not infringe interests of patients. As a result, the existence of non-profitable hospitals can be regarded as an institution response to market imperfections, indicating a low contract cost of ownership form in non-profitable hospitals.

Theory of Interest Group: Doctors Prefer Non-Profitable Hospitals. Bays explained that the reason why doctors prefer non-profitable hospitals is not to minimize hospitals' ownership cost, but to maximize hospitals' collective financial interest. In Bays' eyes, non-profitable organizational form enables doctors to exert a great influence on hospitals and to increase their income by controlling decision makings.

\section{Prevalence of Public Hospitals.}

Hart. (1996) pointed out that due to the incomplete contracts, private manufactures may participate in too many cost-reducing activities and neglect those adverse effects of service quality. Their quality of services is thus degraded. Larger adverse effects of service quality means that government shall supply more services. Customers can neither determine whether the medical quality is affected out of hospitals' intention to reduce cost, nor prevent hospitals from affecting the medical quality in the cost-reducing period. Hence, private property right may be not necessarily appropriate for the hospital industry, which in turn exemplifies the advantage of government's direct supply of medical services.

Gertler argued that establishing public hospitals by the government can guarantee the popularity of medical services (1998). Lacking a complete medical insurance system, governments directly supply medical services in many low-income countries to reduce the charging standard, ensure the medical treatment needs of low-income people, and thus achieve the policy target of "opportunity equality in medical treatments".

\section{Reflection and Summary.}

According to those explanations on the existence of private non-profitable hospitals and public hospitals by foreign scholars, it is hard to conclude which one is more excellent.

In those non-profitable hospitals, the problems like screening patients out of pursuing financial goals will not occur; nevertheless, excessive power of doctors exists occasionally. For instance, a treatment scheme may be formulated out of their interests rather than the patient's.

For lacking of universal medical insurance system, establishing public hospitals by the government can ensure the popularity of medical services and achieve the policy target of opportunity equality in medical treatments. Compared with private hospitals, there are much more wastes in public hospitals. To determine which form is better, the influences of different operation modes on cost and quality must be compared.

\section{Reform Paths of Public Medical Institutions}

Wang Dehua and Zhang Qiong (2009) concluded that a reasonable medical service system should constitute community clinics mainly providing outpatient services and specialized hospitals mainly providing hospitalization services. It doesn't matter whether these medical institutions are public or not. 
In the opinion of Research Group in Chinese Academy of Social Sciences (2008), the key of medical service system reform is to comprehensively deregulate the admittance of medical institutions and carry out corporatization in public medical institutions under the principle of separating government from the institutions. After implementing the reform of "privatization in public medical institutions", there are only differences in scale, service field and service level between hospitals, but no longer differences in administrative rank.

Cai Jiangnan, Xu Xin and Feng Shouyan (2008) suggested that China's reform of public hospitals should avoid the confinement of "separating government regulation from management" between two governmental institutions. The correct direction of new medical reform is to realize the enterprise-like management in public hospitals and enhance operating efficiency; to vigorously strengthen the supervision from the government and private institutions and thus enable public hospitals to meet the demands of patients and the society.

By this token, medical service supply system reform should respond to the market development trend, weight pros and cons, and make changes with the times. In short, China's medical service system reform still has a long way to go.

\section{References}

[1]Wang Yong, Information Economic Explanation for the Excessive rise of China's Medical costs [J], Journal of Chongqing University (natural sciences), 2005(4).

[2]Zhu Hengpeng, Economic Perspectives [J], Institute of Economics, Chinese Academy of Social Sciences, 2009.

[3]Gao Chunliang, Mao Fengfu, Yu Hui. Incentive Mechanism, Financial Burden and Evolution of China's Medical Insurance System: Based on Understanding of Documents Related to the Medical Systems since the Founding, Management World. 2009(4).

[4]Feng Jin, Yu Yangyang, Subsidy Demander or Supplier: Role of Government in Medical Reform, Chinese Reform, 2008(3).

[5]Li Tianpin, Research on Economic Analysis and Medical Reform Policy Orientation of "soaring medical expenses” in the Medical Reform, Journal of Fudan University, 2010.

[6]Li Ling, Let Public Hospitals Return to the Rail of Public Welfare [J], Qiushi Journal, 2008, 7, 56-58.

[7]Yu Baorong, Wang Weifu, Li Youwei, Wang Qing, Guidance of International Health Care Reform Experience [J], Chinese Health Quality Management, 2008(4).

[8]Feng Zhanchun, Zhong Yanjun, Analysis on Influences of Establishing Medical Insurance System with Urban and Rural Residents Covered on Supply of Medical Services [J], Medicine and Society, 2008, 9(21).

[9]Zhu Hengping, Defects in Medical System and Inappropriate Price Regulations, Social Sciences in China, 2007(4), 89-103.

[10]Gu Xin, Heading for Managed Marketization: Strategic Selection of Medical System Reform in China [J], Comparative Economic and Social Systems (Bimonthly), 2005, 6:18-29.

[11]Ding Kuili, Liu Jianping, Dual Customer Service for Excessive Marketization and Insufficient Marketization: Analysis on a Feasible Path in Medical System Reform, Journal of Wuhan University of Science and Technology, 2006, 19 (4). 
[12]E.S. Savas, Privatization and Public-Private Partnerships, Translated by Zhou Zhiren et al., 289-231.

[13]Arrow Kenneth, Uncertainty and the Welfare Economics of Medical Care [M], Amercian Economic Review, 1999.

[14]Bays, C.W., Why Most Private Hospital Are Nonprofit, Journal of Policy Analysis and Management, 1983, 2:366-385.

[15]O Hart, A Shleifer, RW Vishny, The Proper Scope of Government: Theory and an Application to Prisons, The Quarterly Journal of Economics [J], 1996, 112(4):1127-61.

[16]PJ Gertler, On the Road to Social Health Insurance: the Asian Experience [J], World Development, 1998, 26(4):717-732.

[17]Cai Jiangnan, Xu Xin, Feng Shouyan, What Kind of “Separating Government Regulation from Management” Public Hospitals Need, China Hospital CEO, 2008(14): 54-56. 